\title{
ANALISIS TEKNIS KAPAL HIBAH YANG BERBASIS DI PANGANDARAN BERDASARKAN STANDAR BIRO KLASIFIKASI INDONESIA (BKI)
}

\author{
Technical Analysis of Grant Fishing Vessels in Pangandaran Based on Biro Klasifikasi Indonesia (BKI) \\ Standards
}

Oleh:

Izza M Apriliani ${ }^{1}$, Lantun P Dewanti ${ }^{1}$, Heti Herawati ${ }^{1}$, Indah Riyantini ${ }^{1}$, dan Malik Maulana ${ }^{1}$

${ }^{1}$ Departemen Perikanan, Fakultas Perikanan dan Ilmu Kelautan Universitas Padjadjaran Korespondensi: izza.mahdiana@gmail.com

\begin{abstract}
ABSTRAK
Salah satu program KKP adalah bantuan unit kapal untuk nelayan di Pangandaran yang merupakan anggota Kelompok Usaha Bersama (KUB). Permasalahan yang terjadi adalah kapal hibah tidak digunakan oleh nelayan Pangandaran. Riset ini bertujuan menganalisis kesesuaian teknis kapal hibah dengan standar dari Biro Klasifikasi Indonesia (BKI). Riset ini dilaksanakan dari AgustusSeptember 2018, di Kabupaten Pangandaran. Metode penelitian berupa studi kasus yang analisis deskriptif komparatif dengan membandingkan hasil pengukuran tinggi haluan, tebal gading, jarak antara gading dan tebal lambung kapal hibah terhadap standar BKI 1996. Hasil riset menunjukkan bahwa secara umum kapal hibah ukuran 3 GT tidak sesuai dengan standar BKI. Hal ini menyebabkan kapal tidak layak untuk dimanfaatkan.
\end{abstract}

Kata kunci: BKI 1996, hibah, kapal perikanan, konstruksi, Pangandaran

\begin{abstract}
One of the KKP programs is fishing vessel assistance for fishermen in Pangandaran who are members of the Joint Business Group (KUB). The problem that occurs is that the grant ship is not used by Pangandaran fishermen. This research aims to analyze the technical suitability of grant fishing vessels with standards from the Biro Klasifikasi Indonesia (BKI). This research conducted on AugustSeptember 2018, in Pangandaran Regency. The research method is case studies comparative descriptive analysis by comparing the results of measurements of bow height, frame thickness, distance between ivory and hull thickness of the grant ship to the 1996 BKI standard. The results of the research show that in general the 3 GT size grant vessels are not in accordance with BKI standards. This causes the ship to be unfit for use.
\end{abstract}

Key words: BKI 1996, construction, fishing vessels, grants, Pangandaran

\section{PENDAHULUAN}

Indonesia memiliki potensi perikanan laut sesuai dengan riset yang dilakukan oleh Kementerian Kelautan Perikanan (KKP) mencapai 12,5 juta ton/tahun. Potensi ini menjadi peluang bagi nelayan untuk dapat meningkatkan produktivitas penangkapan yang optimal. Pangandaran memiliki potensi sumber daya laut yang luas. Karena itu, potensi sumber daya perikanan tangkap di Pangandaran harus dimanfaatkan secara optimal. Untuk meningkatkan produksi perikanan, kegiatan penangkapan ikan di 
perairan Pangandaran harus didukung oleh sumber daya perikanan yang berkelanjutan (Apriliani et al. 2018).

Berdasarkan wilayah operasi, nelayan Pangandaran menggunakan berbagai jenis alat tangkap untuk menangkap ikan. Kondisi geografis Pangandaran yang berhadapan langsung dengan Samudera Hindia menjelaskan bahwa Pangandaran memiliki sumber daya perikanan laut yang kaya (Apriliani et al., 2018). Hal tersebut belum sepenuhnya didukung unit penangkapan dengan teknologi canggih. Kapal yang digunakan oleh nelayan Pangandaran didominasi oleh perahu motor tempel dengan mesin 15 PK dan daerah penangkapan hanya sekitar 1-2 mil dari garis pantai. Kedalaman perairan pada jarak tersebut tidak lebih dari 50 meter yang dianggap aman untuk operasi penangkapan dengan kapal kecil.

Upaya untuk memanfaatkan potensi di Pangandaran, KKP memiliki program dalam bentuk bantuan kapal hibah kepada nelayan. Program ini adalah bantuan kapal bagi para nelayan Pangandaran yang merupakan anggota Kelompok Usaha Bersama (KUB). KKP berharap dalam memberikan hibah kapal ini membuat para nelayan Pangandaran dapat memiliki kapal sendiri. Keberadaan kapal hibah ini diharapkan dapat meningkatkan pendapatan dan sekaligus berdampak pada peningkatan produksi perikanan sehingga dapat memajukan sektor perikanan laut di Pangandaran.

Kondisi kapal hibah yang berbasis di Pangandaran tidak dimanfaatkan nelayan secara optimal. Menurut Maulana (2019) bahwa kondisi fisik kapal yang tidak sesuai dengan sebagaimana mestinya membuat kapal hibah ini tidak dimanfaatkan lagi oleh nelayan. Kondisi konstruksi pada saat pembuatan yang tidak sesuai ini dicurigai menjadi masalah tidak dimanfaatkannya kapal hibah yang telah diberikan. Biro Klasifikasi Indonesia (BKI) merupakan badan yang menangani perihal standar pembuatan kapal di Indonesia, peneliti dalam bidang perkapalan dan pembuat peraturan mengenai standar-standar klasifikasi kapal di Indonesia. Biro Klasifikasi Indonesia telah menerbitkan peraturanperaturan mengenai pembangunan kapal. Salah satunya adalah peraturan konstruksi kapal kayu yang terdapat pada Biro Klasifikasi Indonesia pada tahun 1996 (BKI 1996). Dengan demikian, perlu dilakukan pengecekan kondisi fisik kapal hibah yang bertujuan untuk melihat kesesuaian konstruksi kapal hibah berdasarkan standar yang telah dirumuskan oleh BKI. Pentingnya dilaksanakan penelitian ini adalah untuk mengetahui evaluasi dalam pembentukan kapal selanjutnya.

\section{METODE PENELITIAN}

Penelitian dilakukan pada bulan Agustus-September 2018. Lokasi penelitian adalah TPI Legok Jawa, TPI Madasari, TPI Cikidang, TPI Nusa Wiru, TPI Bojong Salawe dan TPI Batu Karas. Objek penelitian adalah 55 unit kapal hibah oleh Kementrian Kelautan dan Perikanan. Kapal itu memiliki 33 unit kapal hibah 3 GT dan 22 unit kapal hibah 5 GT yang telah mendarat ke 6 TPI di Pangandaran.

Penelitian dilakukan dengan menggunakan metode studi kasus. Studi ini membahas konstruksi kapal hibah oleh KKP yang tidak digunakan oleh para nelayan. Pengambilan data dilakukan pengukuran langsung terhadap kapal hibah tersebut. Bagian-bagian kapal yang diukur panjangnya adalah tinggi haluan, tebal gading, jarak antara gading dan tebal lambung kapal, sesuai dengan ketentuan BKI 1996. Data yang diperoleh dianalisis secara deskriptif komparatif dengan standar BKI 1996 yang dapat dilihat pada Tabel 1. 
Tabel 1 Standar BKI 1996

\begin{tabular}{clc}
\hline No & \multicolumn{1}{c}{ Bagian Kapal } & Nilai Standar $(\mathrm{cm})$ \\
\hline 1 & Tinggi haluan & 215 \\
2 & Ketebalan gading & 6,20 \\
3 & Jarak antara gading & 28,00 \\
4 & Ketebalan lambung kapal & 1,13 \\
\hline
\end{tabular}

\section{HASIL DAN PEMBAHASAN}

Linggi haluan dibangun dengan kemiringan $\pm 45^{\circ}$ dari lunas, linggi haluan diikatkan dengan memasangkan baut yang disatukan dengan lunas (Nasution \& Hutauruk, 2016). Selain sudut kemiringannya, tinggi dari linggi haluan menjadi faktor penentu dalam pelayaran kapal karena linggi haluan merupakan bagian pertama yang berpapasan dengan gelombang dan ombak air ketika kapal sedang bermanuver di atas permukaan air laut dengan ketinggian yang tepat dan sesuai, linggi haluan dapat meminimalisir air yang masuk ke dalam kapal. Selain itu linggi haluan berfungsi sebagai pembelah gelombang dan ombak air sehingga mempermudah arah gerak kapal di atas air. Perbandingan ukuran konstruksi linggi haluan kapal hibah KKP yang berbasis di Pagandaran adalah seperti ditunjukkan oleh Tabel 2.

Tabel 2 Hasil pengukuran linggi haluan kapal

\begin{tabular}{|c|c|c|c|c|c|c|c|}
\hline \multirow[b]{2}{*}{ GT } & \multicolumn{2}{|c|}{ Kapal Hibah } & \multirow{2}{*}{$\begin{array}{c}\text { Klasifikasi } \\
\text { BKI (cm) }\end{array}$} & \multicolumn{2}{|c|}{ Selisih } & \multirow[b]{2}{*}{ Keterangan } & \multirow{2}{*}{$\begin{array}{c}\text { Nomor } \\
\text { Tabel BKI }\end{array}$} \\
\hline & $\begin{array}{l}\text { Min } \\
(\mathrm{cm})\end{array}$ & $\begin{array}{l}\text { Maks } \\
(\mathrm{cm})\end{array}$ & & $\begin{array}{l}\text { Min } \\
(\mathrm{cm})\end{array}$ & $\begin{array}{l}\text { Maks } \\
(\mathrm{cm})\end{array}$ & & \\
\hline 3 & 177 & 206 & \multirow{2}{*}{215} & -38 & -9 & $\begin{array}{c}\text { Dibawah } \\
\text { Standar }\end{array}$ & \multirow{2}{*}{ 1a } \\
\hline 5 & 192 & 220 & & -23 & 5 & Sesuai Standar & \\
\hline
\end{tabular}

Keterangan:

(-) Kurang dari Standar BKI

(+) Lebih dari Standar BKI

Kapal hibah yang berukuran 3 GT memiliki tinggi linggi haluan antara 177-206 cm. Nilai tersebut jika dibandingkan dengan standar BKI $(215 \mathrm{~cm})$, kapal hibah memiliki kekurangan sebesar 9$38 \mathrm{~cm}$. Tinggi linggi haluan kapal hibah dengan ukuran 3 GT termasuk dibawah standar BKI. Rendahnya tinggi linggi haluan dapat menyebabkan air masuk ke dalam kapal. Berbeda pada kapal hibah yang berukuran 5 GT memiliki tinggi linggi haluan antara 192-220 cm yang memiliki selisih antara -23 sampai $5 \mathrm{~cm}$. Tinggi linggi haluan beberapa kapal berada dalam standar BKI. Hal ini menjelaskan kapal tersebut sesuai dan dapat dimanfaatkan dengan baik.

Pada prinsipnya dalam pelaksanaan pembuatan kapal modern terletak pada konstruksi pemasangan gading, bentuk papan kulit mengikuti bentuk dan kedudukan gading (Jokosisworo \& Santosa, 2016). Bentuk badan kapal yang sesuai dan kekokohan kapal, menjadi prioritas utama dalam pembuatan kapal. Menciptakan bentuk dan kekokohan kapal yang ideal perlu ditunjang dengan kekuatan gading yang sesuai. Perbandingan ukuran ketebalan gading kapal hibah adalah seperti ditunjukkan oleh Tabel 3. 
Tabel 3 Hasil pengukuran ketebalan gading

\begin{tabular}{|c|c|c|c|c|c|c|c|}
\hline \multirow[b]{2}{*}{ GT } & \multicolumn{2}{|c|}{ Kapal Hibah } & \multirow{2}{*}{$\begin{array}{c}\text { Klasifikasi } \\
\text { BKI (cm) }\end{array}$} & \multicolumn{2}{|c|}{ Selisih } & \multirow[b]{2}{*}{ Keterangan } & \multirow{2}{*}{$\begin{array}{c}\text { Nomor } \\
\text { Tabel BK }\end{array}$} \\
\hline & $\begin{array}{l}\text { Min } \\
(\mathrm{cm})\end{array}$ & $\begin{array}{l}\text { Maks } \\
(\mathrm{cm})\end{array}$ & & $\begin{array}{l}\text { Min } \\
(\mathrm{cm})\end{array}$ & $\begin{array}{l}\text { Maks } \\
(\mathrm{cm})\end{array}$ & & \\
\hline 3 & 3.38 & 3.56 & \multirow{2}{*}{6.2} & $-2,82$ & $-2,64$ & $\begin{array}{l}\text { Dibawah } \\
\text { Standar }\end{array}$ & \multirow{2}{*}{$3 c, 6 a 1$} \\
\hline 5 & 7.21 & 7.5 & & 1,01 & 1,3 & Sesuai Standar & \\
\hline
\end{tabular}

Keterangan:

(-) Kurang dari Standar BKI

(+) Lebih dari Standar BKI

Kapal hibah yang berukuran 3 GT memiliki ketebalan gading antara 3,38-3,56 cm, dibandingkan dengan standar BKI $(6,2 \mathrm{~cm})$, kapal hibah memiliki kekurangan sebesar 2,64-2,82 cm. Ketebalan gading kapal hibah dengan ukuran 3 GT termasuk dibawah standar BKI. Ketebalan yang kurang dan tidak sesuai dikhawatirkan rangka kapal tidak kokoh menahan kapal dari ombak ataupun gelombang. Sehingga dapat mengancam keselamatan nelayan ketika kapal sedang beroperasi di lautan lepas dengan cuaca yang buruk.

Kapal hibah yang berukuran 5 GT memiliki ketebalan gading antara 7,21-7,5 cm, memiliki selisih antara 1,01-1,3 cm. Tebal gading yang lebih besar mengindetifikasikan bahwa kapal telah sesuai sehingga kapal layak untuk digunakan dan dapat menjamin nelayan yang menggunakannya.

Pada pembangunan kapal mengutamakan kekuatan pada rangka (gading) meskipun memiliki jarak yang relatif besar, sistem tersebut mempunyai kekuatan yang kokoh dalam prinsip pembangunannya (Dewa \& Muhammad, 2010). Perbandingan ukuran jarak antar gading kapal hibah yang berbasis di Pagandaran disajikan pada Tabel 4.

Tabel 4 Hasil pengukuran jarak antara gading

\begin{tabular}{|c|c|c|c|c|c|c|c|}
\hline \multirow[b]{2}{*}{ GT } & \multicolumn{2}{|c|}{ Kapal Hibah } & \multirow{2}{*}{$\begin{array}{c}\text { Klasifikasi } \\
\text { BKI (cm) }\end{array}$} & \multicolumn{2}{|c|}{ Selisih } & \multirow[b]{2}{*}{ Keterangan } & \multirow{2}{*}{$\begin{array}{c}\text { Nomor } \\
\text { Tabel BK }\end{array}$} \\
\hline & $\begin{array}{l}\text { Min } \\
(\mathrm{cm})\end{array}$ & $\begin{array}{l}\text { Maks } \\
(\mathrm{cm})\end{array}$ & & $\begin{array}{l}\text { Min } \\
(\mathrm{cm})\end{array}$ & $\begin{array}{l}\text { Maks } \\
(\mathrm{cm})\end{array}$ & & \\
\hline 3 & 44,5 & 46 & \multirow[b]{2}{*}{28} & 16,5 & 18 & $\begin{array}{l}\text { Diatas } \\
\text { Standar }\end{array}$ & \multirow[b]{2}{*}{$3 c, 6 a 1$} \\
\hline 5 & 69 & 70 & & 41 & 42 & $\begin{array}{l}\text { Diatas } \\
\text { Standar }\end{array}$ & \\
\hline
\end{tabular}

Keterangan:

(-) Kurang dari Standar BKI

(+) Lebih dari Standar BKI

Jarak antar gading sesuai dengan standar BKI memiliki jarak sebesar $28 \mathrm{~cm}$. Kapal hibah $3 \mathrm{GT}$ memiliki jarak antar gading antara 44,5-46 cm dan kapal hibah yang berukuran 5 GT memiliki jarak gading antara 69-70 cm. Kedua kapal hibah memiliki ukuran jarak antar gading yang lebih besar dibandingkan standar BKI. Nasution dan Hutauruk (2016) menyatakan bahwa jika ukuran melebihi standar BKI, maka kekuatan dan beban yang diterima konstruksi kapal akan lebih baik dari ukuran minimum ketentuan kelas pada jenis bahan sama. Sehingga memberikan jaminan kekuatan konstruksi yang memopang keselamatan pelayaran pada daerah operasi dengan menggunakan kapal tersebut.

Kulit lambung kapal yang menggunakan fiberglass, pada umumnya memiliki bahan dasar berupa resin, katalis, kalsium karbonat, matt, cobalt blue dan wax. Dibuat dalam proses laminasi diusahakan lapisan tersebut harus rata dan tidak terjadi peranginan yang menyebabkan lapisan tersebut pecah atau rapuh. Untuk lapisan kulit lambung terdapat 9 lapisan yang menyusun (Ikhsan, 2010). 
Perbandingan ukuran tebal kulit lambung kapal hibah yang berbasis di Pagandaran adalah seperti ditunjukkan oleh Tabel 5.

Tabel 5 Hasil pengukuran ketebalan kulit lambung kapal

\begin{tabular}{|c|c|c|c|c|c|c|c|}
\hline \multirow[b]{2}{*}{ GT } & \multicolumn{2}{|c|}{ Kapal Hibah } & \multirow{2}{*}{$\begin{array}{l}\text { Klasifikasi } \\
\text { BKI (cm) }\end{array}$} & \multicolumn{2}{|c|}{ Selisih } & \multirow[b]{2}{*}{ Keterangan } & \multirow{2}{*}{$\begin{array}{c}\text { Nomor } \\
\text { Tabel BKI }\end{array}$} \\
\hline & $\begin{array}{l}\text { Min } \\
(\mathrm{cm})\end{array}$ & $\begin{array}{l}\text { Maks } \\
(\mathrm{cm})\end{array}$ & & $\begin{array}{l}\text { Min } \\
(\mathrm{cm})\end{array}$ & $\begin{array}{c}\text { Maks } \\
(\mathrm{cm})\end{array}$ & & \\
\hline 3 & 0,44 & 0,71 & \multirow{2}{*}{1,13} & $-0,69$ & $-0,42$ & $\begin{array}{l}\text { Dibawah } \\
\text { Standar }\end{array}$ & \multirow{2}{*}{ Bab 3.2, 6a1 } \\
\hline 5 & 1,25 & 1,38 & & 0,12 & 0,25 & $\begin{array}{c}\text { Diatas } \\
\text { Standar }\end{array}$ & \\
\hline
\end{tabular}

Keterangan:

(-) Kurang dari Standar BKI

(+) Lebih dari Standar BKI

Kapal hibah yang berukuran 3 GT memiliki ketebalan kulit lambung kapal antara 0,44-0,71 cm, dibandingkan dengan standar BKI adalah 1,13 cm. Kapal hibah memiliki kekurangan sebesar 0,42-0,69 cm. Ketebalan kulit lambung kapal hibah dengan ukuran 3 GT termasuk dibawah standar BKI. Ketebalan yang tidak sesuai berbahaya bagi keselamatan nelayan dalam pelayaran karena akan lebih mudah mengalami kerusakan ataupun kebocoran kapal. Berbeda dengan kapal hibah yang berukuran 5 GT memiliki ketebalan kulit lambung kapal antara 1,25-1,38 cm yang memiliki selisih antara 0,12$0,25 \mathrm{~cm}$. Tebal kulit lambung kapal yang lebih besar mengindetifikasikan bahwa kapal telah sesuai.

\section{KESIMPULAN DAN SARAN}

Tinggi haluan, ketebalan gading dan kulit lambung kapal pada kapal hibah 3 GT tidak sesuai dengan standar BKI. Jarak antara gading merupakan satu-satunya parameter yang sesuai dengan standard BKI. Kapal hibah dengan ukuran 5 GT seluruh parameternya sesuai dengan standar yang ditetapkan BKI 1996. Tinggi haluan, ketebalan gading, jarak antar gading dan kulit lambung kapal yang tidak sesuai dengan BKI menyebabkan kapal tidak layak untuk dimanfaatkan.

\section{DAFTAR PUSTAKA}

Apriliani IM, Nurrahman YA, Dewanti LP, Herawati H. 2018. Determination of potential fishing ground for hairtail (Trichiurus sp.) fishing based on chloropyll-a distribution and sea surface temperature in Pangandaran Waters, West Java, Indonesia. AACL Bioflux. 11(4):1047-1054.

[BKI] Biro Klasifikasi Indonesia. 1996. Buku Peraturan Klasifikasi dan Konstruksi Kapal Kayu. Jakarta (ID): BKI.

Dewa S, Muhammad AH. 2010. Teknologi Pembangunan Kapal Kayu Tradisional di Tanahberu Kabupaten Bulukumba. Prosiding Seminar Nasiona Teori dan Aplikasi Teknologi Kelautan. 9 Desember 2010.

Ikhsan, M. 2016. Analisa kebutuhan material kapal 3 GT untuk galangan kapal multifungsi. Jurnal Kapal. 13(3):135-141.

Jokosisworo, S. dan Santosa, A. W. B. 2016. Analisa teknis KM Putra Bimantara III menurut peraturan konstruksi kapal kayu BKI. Jurnal Kapal. 13(3):6-14.

Nasution, P. dan Hutauruk, R. M. 2016. Analisis konstruksi kapal nelayan tradisional di Kabupaten Bengkalis Provinsi Riau. Jurnal Perikanan dan Kelautan. 21 (1):7-17. 
Nur I and Sunarto PJ. 2018. Design of fishing boat for Pelabuhanratu Fishermen as one of effort to increase production of capture fisheries. Journal of Physics: Conference Series. 962(2018):1-8.

Suprapto D, Purnomo PW, Sulardiono B. 2014. Aquatic productivity analysis based on the relationship between physicaland chemical of benthic Sediment with NO3 and PO4 in the estuarine of Tuntang River. Indonesian Journal of Fisheries Science and Technology. 10(1):56-61. 